\title{
Structural optimization of the main nozzle in an air- jet loom based on orthogonal test method
}

\begin{abstract}
Due to having more complicated inner structural features and obvious influence on the air-jet performance arising from the acceleration tube, the structural optimization of the main nozzle for an air-jet loom is still a difficult problem. Naturally, traditional design method for the nozzle will still prolong the time of type approval and increase the design cost. In this paper, orthogonal test method and numerical simulation are utilized to optimize the structure of subsonic acceleration zone; the optimal structure parameters matched with different air supply pressure are obtained. Results indicate that the external diameter of the nozzle needle has a negative influence on the airflow velocity whereas the diameter of the acceleration tube presents positive effect. Both of them play an important influence on the flow field of the main nozzle field and the other structural parameters have little influence on that. This research is also benefit for structural optimization of the main nozzle and energy conservation of an air-jet loom.
\end{abstract}

Keywords: air-jet loom, main nozzle, structural optimization, flow field, orthogonal test method, rectification process, flow field, jet performance, acceleration tube, numerical integration, adiabatic pipe flow, weft yarn, weft insertion, axial length, needle tip
Volume I Issue 5 - 2017

Xiangjun Lan, Dingding Liu, Zhihua Feng

Soochow University, China

Correspondence: Zhihua Feng, School of Mechanical and Electric Engineering, Soochow University,

Suzhou 21502I, China, Email zhfeng@suda.edu.cn

Received: March 31, 2017 | Published: April 26, 2017

\section{Introduction}

In an air-jet loom, the weft yarn is dragged by the high-speed air flow to pass through the shed to carry out the weft insertion process, where the air flow may reach a critical condition at the nozzle throat zone and even exceed sonic state at outside of the acceleration tube after modulation and rectification process. At the same time, the weft yarn has had a full interaction with high-speed air flow and is accelerated to the needed velocity. So the main nozzle is really the heart of an air-jet loom, and Studies on its pneumatic behaviors have been intermittently pursued over the past few decades. For instance, Ishida and Okajima ${ }^{1,2}$ experimentally measured the static pressure and air velocity distribution under different acceleration tube length and air supply pressure in the flow field of main nozzle. Their results showed that the attenuate law of air velocity along axial direction and radial direction is similar, and the air velocity of main nozzle exit is not relevant to acceleration tube length. Mohamed and Salama ${ }^{3,4}$ tested the air velocity and characteristic of the flow turbulence with different main nozzle structures, and they also got the relationship between various geometries of the main nozzle and the jet performance. ${ }^{5}$ Researched the effect of different acceleration tube geometries on flow field. Due to the complicated inner structure of main nozzle, it is difficult to directly place a sensor to measure the air flow. ${ }^{6}$ Studied the effect of the length of the acceleration tube and the shape of nozzle needle on flow field through two-dimensional numerical simulation. ${ }^{7-9}$ systematically researched the flow field characteristics of main nozzle by three-dimensional numerical simulation and some structural parameters of the main nozzle were also dealt with.

In this paper, the drag force of weft yarn is obtained by the theory of one dimensional steady adiabatic pipe flow and equation of gas state. The drag force under different types of air supply pressure is computed by numerical integration, which is an important measurement criterion for the jet performance of the main nozzle.
Afterwards number of rectifier tank, external diameter of needle tip, distance between needle tip and rectifier tank, $\alpha$ face projected length and diameter of acceleration tube are optimized by the combination of both numerical simulation and orthogonal test method.

\section{Design objective and measured criterion}

\section{Design objective}

The main nozzle is a key component of weft insertion system in an air-jet loom. The air chamber and rectifier tank are used to collimate and accelerate the air flow parallel to weft insertion direction. At the same time, a conical sleeve is designed to form a subsonic acceleration zone. When the air flow passed through nozzle throat which is an annual slot, it may exceed sonic speed and produce a negative zone in weft injection region. So the weft yarn is inhaled into main nozzle through weft insertion passage. In the acceleration tube, the air flow is accelerated again so as to obtain a higher speed to obtain the needed kinetic energy. The rotation of advanced air-jet loom has reached $800 \sim 1000 \mathrm{r} / \mathrm{min}$ with weft insertion speed of $3000 \mathrm{~m} / \mathrm{min}$, and the weft yarn should fly across the shed within $20 \sim 30 \mathrm{~ms}$. So the main nozzle plays an important role in accelerating yarns and achieving sonic velocity at the main nozzle exit is always the design objective of it

\section{Measurement criterion}

Air velocity in the main nozzle: The weft yarn is accelerated by abundant friction with high-speed air flow, where the drag force is depended on the relative speed between yarn and jet flow. The corresponding formula is shown as:

$$
F=\frac{1}{2} C_{f} \rho \pi d(V-U)^{2} L
$$

where $F$ is the drag force, $C_{f}$ is the coefficient of drag force, $\rho$ is the air density, $\mathrm{d}$ is the weft yarn diameter, $V$ is the air velocity, 
$U$ is the yarn velocity, and $\mathrm{L}$ is the yarn length subject to air. From Equation (1) we can find the drag force mainly depends on relative speed and air density in main nozzle. Based on one-dimensional pipe flow theory, the velocity of main nozzle exit can reflect the inner flow condition of the main nozzle, which naturally is the most significant measurement criterion.

Negative pressure zone of the needle tip exit: As the result of highspeed jet flow, negative pressure zone is produced at the needle tip. The weft yarn is inhaled to main nozzle through weft guide passage and then it enters into weft ejection zone and acceleration zone. It is thus clear that a negative pressure zone is necessary for weft insertion in Figure 1.

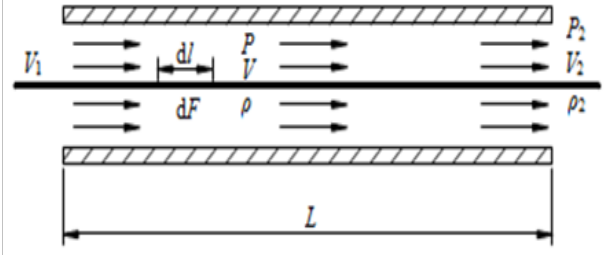

Figure I Schematic of the weft insertion.

Drag force: The friction between yarn and airflow is the motive power for leaping and produces the so-called drag force, which will counteract the friction between yarn and the thread guide, the dynamic tension of ballooning and the static tension in weft accumulator. In order to analyze and calculate the force, we assumed that the weft yarn move along with the axis of acceleration tube, and the drag force exerted on infinitesimal segment is

$$
d F=\frac{1}{2} C_{f} \rho \pi d(V-U)^{2} d l
$$

As the flow velocity at needle tip may exceed the speed of sound whereas the diameter of acceleration tube keeps constant, thus the air flow is a typical Fanno one. Then the differential equation of air velocity along the axial direction is

$$
\begin{aligned}
& \frac{4 f K}{D} d l=\frac{1-M^{2}}{M^{2}\left[1+M^{2}(K-1) / 2\right]} \frac{d M^{2}}{M^{2}} \\
& F(M)=-U^{2} / 3 M^{3}+C U / M^{2}+(K+1) U^{2} / 2-C^{2} / M+(K+1) U C \ln (M)+\left[\left(K^{2}-1\right) U^{2}-2(K+1) C^{2}\right] / \sqrt{8(K-1)} \times \arctan (\sqrt{(K-1) / 2} M)
\end{aligned}
$$

Where $\mathrm{M}$ is the Mach number, $\mathrm{D}$ is the acceleration tube diameter, $\mathrm{f}$ is the frictional coefficient, and $\mathrm{K}$ is the ratio of special heat.

The inlet flow ought to be the same as outlet flow based on the continuity relation, where $\mathrm{D}$ is constant. We obtain

$$
\rho V=\rho_{2} V_{2}
$$

From the law of conservation of energy, the stagnation temperature of the nozzle exit is equal to that of air tank. Thus, we obtain

$$
C_{P} T_{0}=C_{P} T+V_{2}^{2} / 2
$$

Where $C_{P}$ is specific heat at constant pressure and $T_{0}$ is stagnation temperature. Temperature of acceleration tube exit $\mathrm{T}_{2}$ is represented as

$$
T_{2}=T_{0}-V_{2}^{2} / 2 C_{P}
$$

From the ideal gas state equation (i.e. $P=\rho R T$ ) and equations (4) and (6), air density of the acceleration tube is

$$
\rho_{2}=P_{2} /\left[R\left(T_{0}-V_{2}^{2} / C_{P}\right)\right]
$$

Where $P_{2}$ and $V_{2}$ are static pressure and air velocity of nozzle exit, respectively. Then from equations (2), (3), (4) and (7), we obtain

$$
d F=\frac{\pi d D P_{2} V_{2} C_{f}}{8 f K R C\left(T_{0}-V_{2}^{2} / 2 C_{P}\right)} \cdot \frac{(C M-U)^{2}}{M} \cdot \frac{1-M^{2}}{M^{2}\left[1+M^{2}(K-1) / 2\right]} \frac{d M^{2}}{M}
$$

Where $R$ is gas constant and $C$ is velocity of sound.

As the result of short length of acceleration tube, coefficient $\mathrm{C}_{\mathrm{f}}$ can be taken as a constant, thus, we have

$$
F=\frac{\pi d D C_{f}}{5.6 f R C} \cdot \frac{P_{2} V_{2}}{T_{0}-V_{2}^{2} / 2 C_{P}} \times\left[F\left(M_{2}\right)-F\left(M_{1}\right)\right]
$$

Substituting K into the above formula, we have

$$
F(M)=-U^{2} / 3 M^{3}+C U / M^{2}+1.2 U^{2}-C^{2} / M+2.4 U C \ln (M)+\left(0.24 U^{2}-1.2 C^{2}\right) \times \sqrt{5} \arctan (M / \sqrt{5})
$$

At the beginning of weft insertion, the velocity of weft yarn is equal to zero (i.e. $U=0$ ), so the static weft drag force is

$$
F=\frac{\partial d D C_{f} C}{5.6 f R} \cdot \frac{P_{2} V_{2}}{T_{0}-V_{2}^{2} / 2 C_{P}} \times\left\{\frac{1}{M_{1}}-\frac{1}{M_{2}}+1.2 \sqrt{5}\left[\arctan \left(M_{1} / \sqrt{5}\right)-\arctan \left(M_{2} / \sqrt{5}\right)\right]\right\}
$$

From Equation (11) we can find that the drag force is direct proportional to parameters of $D, C_{f}, d$ and $P_{2}$. As the acceleration tube length $L$ has an effect on $M_{1}$ and $M_{2}$, it is also a significant influencing factor for drag force which is the most important measured criterion of the jet performance of the main nozzle. This paper researched the cotton yarn and the relative parameters are defined as follows: $d=0.3352 \mathrm{~mm}, \quad C_{f}=0.03, f=0.004, \quad C=340 \mathrm{~m} / \mathrm{s}, \quad R$ $=287 \mathrm{~J} / \mathrm{Kg} \cdot \mathrm{K}, T_{0}=296 \mathrm{~K}, C_{P}=1004.5 \mathrm{~J} / \mathrm{Kg} \cdot \mathrm{K}$, and $K=1.4$.

The stress range of weft yarn in main nozzle is divided into four parts as shown in Figure 2. The weft guide passage is the first stress area where the yarn is brought into the main nozzle by negative pressure. The backflow zone is the second section where the drag force is decreased slightly because of the counterblast. The airflow mixing zone is the third section where the yarn is dragged by forward airflow again. The weft acceleration zone is the last section where the yarn is accelerated to the needed velocity with the high-speed airflow. The calculation method of each section is illustrated as follows. The static drag force of weft yarn in previous three sections is obtained by numerical integration with axial length in Equation (2), where the air density $P_{2}$ and velocity $\mathrm{V}$ are obtained from numerical simulation. And then in the last section, the drag force is obtained from the Equation 
(11), where the parameters of both ends of the acceleration tube such as $P_{2}, V_{2}, M_{1}$ and $M_{2}$ gained by numerical simulation.

From the previous research in consistency between numerical simulation and experiment, the weft drag force calculated by means of numerical simulation is possible and reliable.

\section{Analysis of structural parameter}

In this paper, a combination of numerical simulation and orthogonal test method are used to optimize the key structure of main nozzle such as number of rectifier tank, external diameter of needle tip, distance between needle tip and rectifier tank, $\alpha$ face projected length and diameter of acceleration tube. So it reflected the influence of multiple parameters changed meanwhile on flow field and the most optimal structure is obtained.

Figure 3 shows the main structural parameters of the nozzle for optimization. As the flow passage is formed by nozzle needle and nozzle body, where the airflow is rectified and accelerated to high speed, we select these parameters as research object and make further improvement on jet performance of the main nozzle.

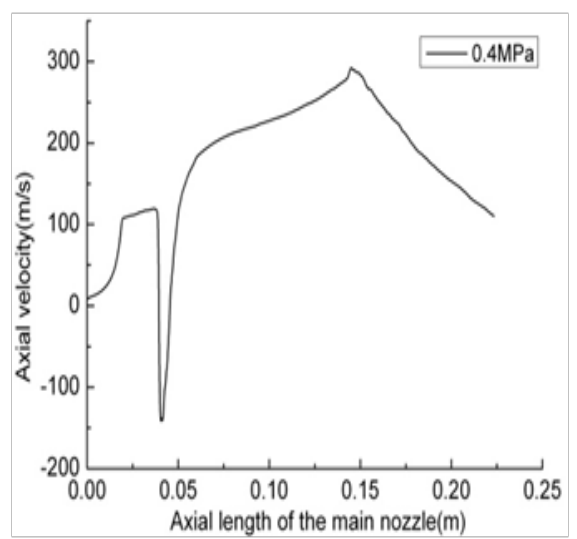

Figure $\mathbf{2}$ Schematic of the weft traction force in stepwise method.
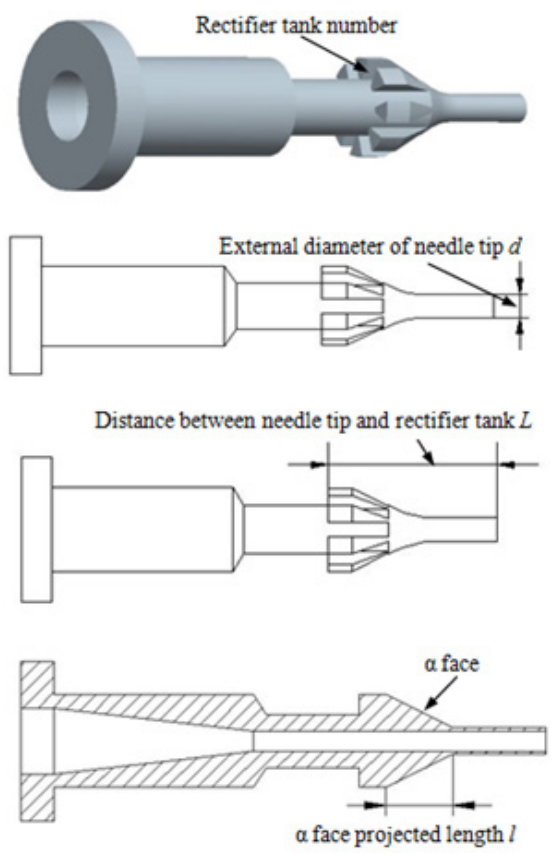

Figure 3 Primary structural parameters of main nozzle.

\section{Orthogonal experiment design}

\section{Introduction of orthogonal test method}

In order to confirm the effect of main nozzle structure on inner flow field, it is need to carry out thousands of experiment. For example, when there are five factors and four levels on each of them, it is needed to test 1024 times.

As the result of the limit of manufacturing and experimental condition, it is impossible to carry out such an experiment; however, orthogonal test method can meet the demand.

Orthogonal test method is one of multiple factors and multiple levels, where only typical experiment is carried out from the full combination method and it has the characteristic of uniform distribution. Each level of factors is distributed more reasonable in experimental program. So we could obtain the most satisfied results by the least consumption. Orthogonal test method has such advantages compared with full combination project: reducing the consumption of manpower and material resource, determining the effect of each factor on measured criterion, and confirming the experiment orientation for future.

The process of orthogonal test method is explained as follows: determining experiment factor and level, selecting appropriate orthogonal table, listing the test scheme and result, analyzing the measured criterion, obtaining the optimal model and verifying result. With the improvement of computational fluid dynamics it is feasible to use software CFD for numerical simulation of flow field and structure optimization. So we adopt Fluent to do numerical experiment of orthogonal program, in order to study the influence of each parameter on nozzle flow field and obtain the optimal structures under different air supply pressure.

\section{Numerical scheme and evaluation criterion}

In orthogonal test, the main structure parameters influencing the flow field are selected as research object and others keep the same. In this paper, number of rectifier tank (i.e. $n$ ), external diameter of needle tip (i.e. $d$ ), distance between needle tip and rectifier tank (i.e. $L$ ), a face projected length (i.e. 1) and diameter of acceleration tube (i.e. $D$ ) are the optimal factors which are in four levels. As shown in Table 1, there are sixteen experiment scheme confirmed by orthogonal table $\mathrm{L}_{16}\left(4^{5}\right)$. Then the three-dimensional geometry model of the scheme from orthogonal table is established by Pro/E, and the flow condition is illustrated from the result of numerical simulation by software Fluent. In the paper, air velocity of the main nozzle exit and static weft drag force are the evaluation criterion of jet performance and they are obtained by the method above mentioned.

Table I Level of each factor in orthogonal test

\begin{tabular}{llllll} 
Factor level & A & B & C & D & E \\
\cline { 2 - 6 } & n & D & d & L & I \\
\hline 1 & 6 & 3 & 2 & 12 & 3 \\
2 & 8 & 3.5 & 2.2 & 14 & 4 \\
3 & 10 & 4 & 2.4 & 16 & 5 \\
4 & 12 & 4.5 & 2.6 & 18 & 6
\end{tabular}




\section{Numerical result and analysis}

The comprehensive balance method is always used to analyze the result of multiple-index orthogonal test. It means that a subtraction between maximum and minimum of measured criterion is done and the range is obtained. From the analyzed range, we have obtained the relationship between each factor and evaluation index. Then the general optimal model is obtained with the comparison between theoretical method and practical experience. In this paper, the structure optimization under the air supply pressure of $0.3 \mathrm{MPa}$ is carried out and the analytical method could be also used to other conditions.

Table 2 shows the air velocity of nozzle exit and static weft drag force of the different conditions from numerical simulation. $\mathrm{k}$ Express the sum of all experimental indexes under the level $\mathrm{i}$, and $\mathrm{Ki}$ is the average. It reflects the affection degree of each factor in evaluation index. The orthogonal test shows the effect of five factors in orders is $\mathrm{B}>\mathrm{C}>\mathrm{A}>\mathrm{D}>\mathrm{E}$ in Table 1. So it is reasonable to select the air velocity of nozzle exit as an evaluation criterion. At the same time, the static drag force is relative to air velocity and density, so that each factor has the same influence law on the two evaluation index. As shown in Figures $4 \& 5$, the curves of the nozzle exit velocity and static drag force varies with the factors and levels. As a whole, each factor has the same influence law on the two evaluation index. As the air supply pressure is low, the average of air velocity of the nozzle exit is lower than $300 \mathrm{~m} / \mathrm{s}$ in all levels of each factor. In this paper, the

Table 2 Range analysis method of outlet velocity $(p=0.3 \mathrm{MPa})$ maximum static drag force of cotton yarn is $0.193 \mathrm{~N}$, which is close to the experimental value. ${ }^{1}$ There are some conclusions obtained as follows:

a. The evaluation index decreases with the increase of rectifier tank number, but the amplitude of variation is smaller than $10 \%$. It is indicated that the factor A has a small influence on flow field of the main nozzle. Considering the process of manufacturing, the air velocity of nozzle exit and weft drag force reach the maximum at the level of 1 .

b. As shown in Table 1, the diameter of acceleration tube has a maximum effect on above two evaluation index. The air velocity and weft drag force is augmented rapidly with the increase of the diameter. When the diameter increases to $4 \mathrm{~mm}$, the evaluation index almost becomes invariant, even if the diameter of acceleration tube is infinitely increased; the evaluation is still not invariant except the sharp increase of energy consumption. Considering the energy consumption and weft insertion effect, the factor B is the best choice at the level of 3 .

c. As the throat area decreases with the increase of the external diameter of needle tip, the airflow rate and density is reduced and the air velocity and weft drag force decreases rapidly. So the evaluation index decreases with the increase of factor $\mathrm{C}$ which has a great effect on flow field second to factor B. The external diameter of acceleration tube is the best at the level of 2 .

\begin{tabular}{|c|c|c|c|c|c|c|c|}
\hline \multirow[t]{2}{*}{ Experiment number } & \multicolumn{5}{|c|}{ Effect factor } & \multirow[t]{2}{*}{ Outlet velocity V(m/s) } & \multirow[t]{2}{*}{ Leakage } \\
\hline & $\mathbf{A}$ & B & c & D & $\mathbf{E}$ & & \\
\hline 1 & 1 & 1 & 1 & 1 & 1 & 273.32 & $N$ \\
\hline 2 & 1 & 2 & 2 & 2 & 2 & 283.18 & $N$ \\
\hline 3 & I & 3 & 3 & 3 & 3 & 288.56 & $\mathrm{~N}$ \\
\hline 4 & 1 & 4 & 4 & 4 & 4 & 285.31 & $\mathrm{~N}$ \\
\hline 5 & 2 & I & 2 & 3 & 4 & 243.1 & $\mathrm{~N}$ \\
\hline 6 & 2 & 2 & 1 & 4 & 3 & 296.38 & $\mathrm{~N}$ \\
\hline 7 & 2 & 3 & 4 & 1 & 2 & 277.96 & $N$ \\
\hline 8 & 2 & 4 & 3 & 2 & 1 & 294.52 & $\mathrm{~N}$ \\
\hline 9 & 3 & I & 3 & 4 & 2 & 204.69 & $\mathrm{~N}$ \\
\hline 10 & 3 & 2 & 4 & 3 & 1 & 236.92 & $\mathrm{~N}$ \\
\hline 11 & 3 & 3 & 1 & 2 & 4 & 311.08 & $Y$ \\
\hline 12 & 3 & 4 & 2 & 1 & 3 & 303.5 & $Y$ \\
\hline 13 & 4 & 1 & 4 & 2 & 3 & $156.4 \mid$ & $\mathrm{N}$ \\
\hline 14 & 4 & 2 & 3 & 1 & 4 & 266.89 & $\mathrm{~N}$ \\
\hline 15 & 4 & 3 & 2 & 4 & 1 & 297.47 & $\mathrm{~N}$ \\
\hline 16 & 4 & 4 & 1 & 3 & 2 & 301.11 & Y \\
\hline KI & 1130.38 & 877.53 & 1181.91 & 1121.73 & 1102.25 & \multirow{4}{*}{\multicolumn{2}{|c|}{ Sum of the indicator of every effect factor }} \\
\hline K2 & 1111.97 & 1083.38 & 1127.3 & 1045.21 & 1066.95 & & \\
\hline K3 & 1056.24 & 1175.08 & 1054.67 & 1069.7 & 1044.89 & & \\
\hline K4 & 1021.89 & 1184.49 & 956.6 & 1083.86 & 1106.39 & & \\
\hline
\end{tabular}


Table Continued.

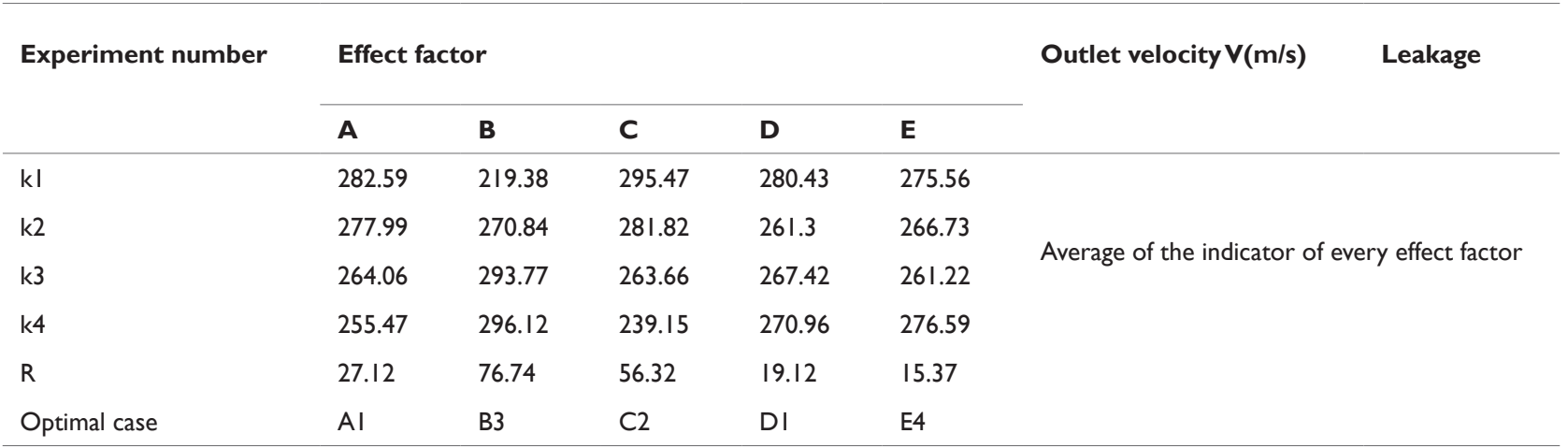

With the increase of distance $L$ between needle tip and rectifier tank, the air velocity and density decreases firstly and then keeps the same. When $L$ increases, the weft ejection zone moves to exit and the energy consumption becomes larger, so the evaluation index has decreased gradually. To a certain degree, the evaluation index remained stable. It is the best for weft insertion that the factor D is at level of 1 .

The projected length range of $\alpha$ face is the least, so it has the least effect on air velocity and weft drag force, where the amplitude of variation is smaller than $10 \%$. As shown in Figure 4, the longer the 1 with narrow acceleration zone is, the greater the velocity acceleration is. When 1 is $6 \mathrm{~mm}$, the evaluation index is the highest.

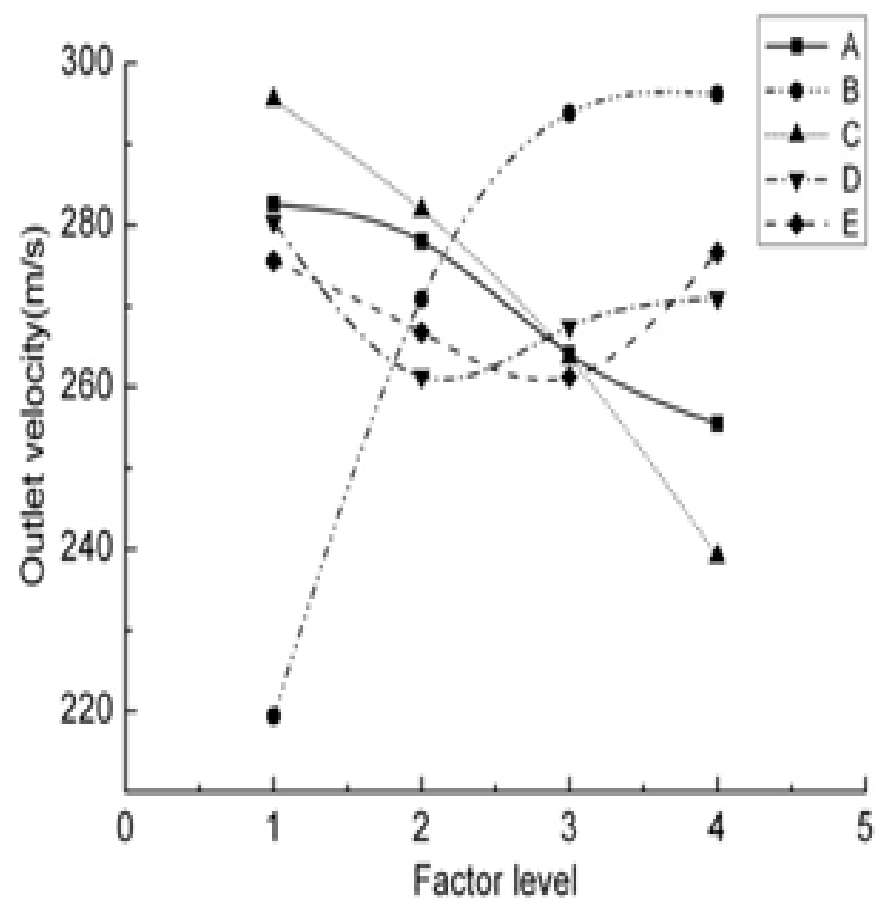

Figure 4 Outlet velocity changed with factor $(p=0.3 \mathrm{MPa})$.

The optimal structure combination of the main nozzle is obtained from the range analysis (i.e. $\mathrm{A}_{1} \mathrm{~B}_{3} \mathrm{C}_{1} \mathrm{D}_{1} \mathrm{E}_{4}$ ), where the air velocity and drag force reach the maximum. Considering the factor affecting relationship, the assembly of $\mathrm{A}_{3} \mathrm{~B}_{3} \mathrm{C}_{1} \mathrm{D}_{2} \mathrm{E}_{4}$ in numerical simulation is the closest to the optimal scheme. It is indicated that the analysis method of structure optimization for the main nozzle is correct and reliable from (Table 2) (Table 3). When the throat area is oversize, there is an air leakage phenomenon in weft guide passage, and the ballooning is produced in weft inlet by counterblast. So the weft drag force is decreased and sometimes even lead failure of weft insertion and weft stoppage. In another word, the air leakage phenomenon is not allowed.

From the Table 2, there is an air leakage phenomenon in optimal structure combination of numerical simulation. Taking into account energy consumption and process, expanding the external diameter of nozzle needle (i.e. decreasing throat area) is taken to prevent the leakage phenomenon at weft inlet. With the combination of numerical simulation and range analysis, there is not an air leakage phenomenon in assembly of $\mathrm{A}_{4} \mathrm{~B}_{3} \mathrm{C}_{2} \mathrm{D}_{4} \mathrm{E}_{1}$ and the evaluation index is close to the optimal scheme of range analysis, so that it is feasible for expanding the external diameter of nozzle needle to $2.2 \mathrm{~mm}$. In the end, the assembly of $\mathrm{A}_{1} \mathrm{~B}_{3} \mathrm{C}_{2} \mathrm{D}_{1} \mathrm{E}_{4}$ is selected as the optimal structure under the air supply pressure of $0.3 \mathrm{MPa}$. With the verifying of the numerical simulation, the air velocity of nozzle exit of the model reached $303.7 \mathrm{~m} / \mathrm{s}$ (i.e. $0.9 \mathrm{M}$ ), which satisfied the weft insertion requirement.

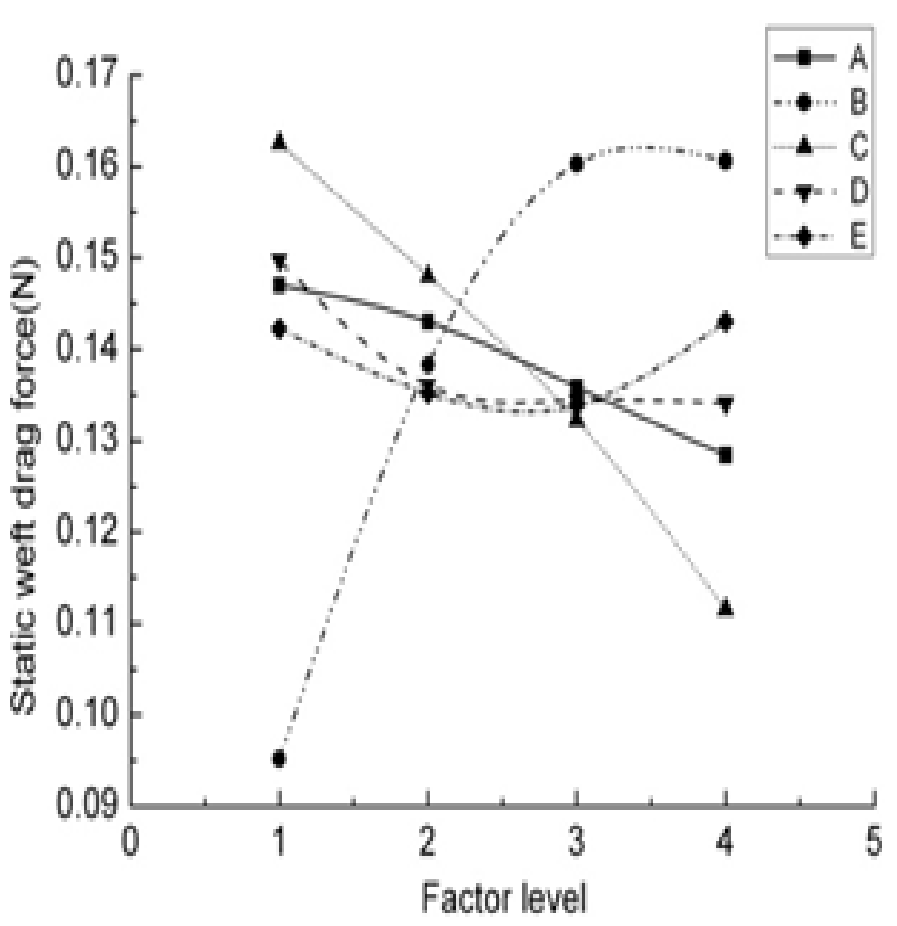

Figure 5 Weft traction force changed with factor $(p=0.3 \mathrm{MPa})$. 
Table 3 Range analysis method of weft traction force $(p=0.3 \mathrm{MPa})$

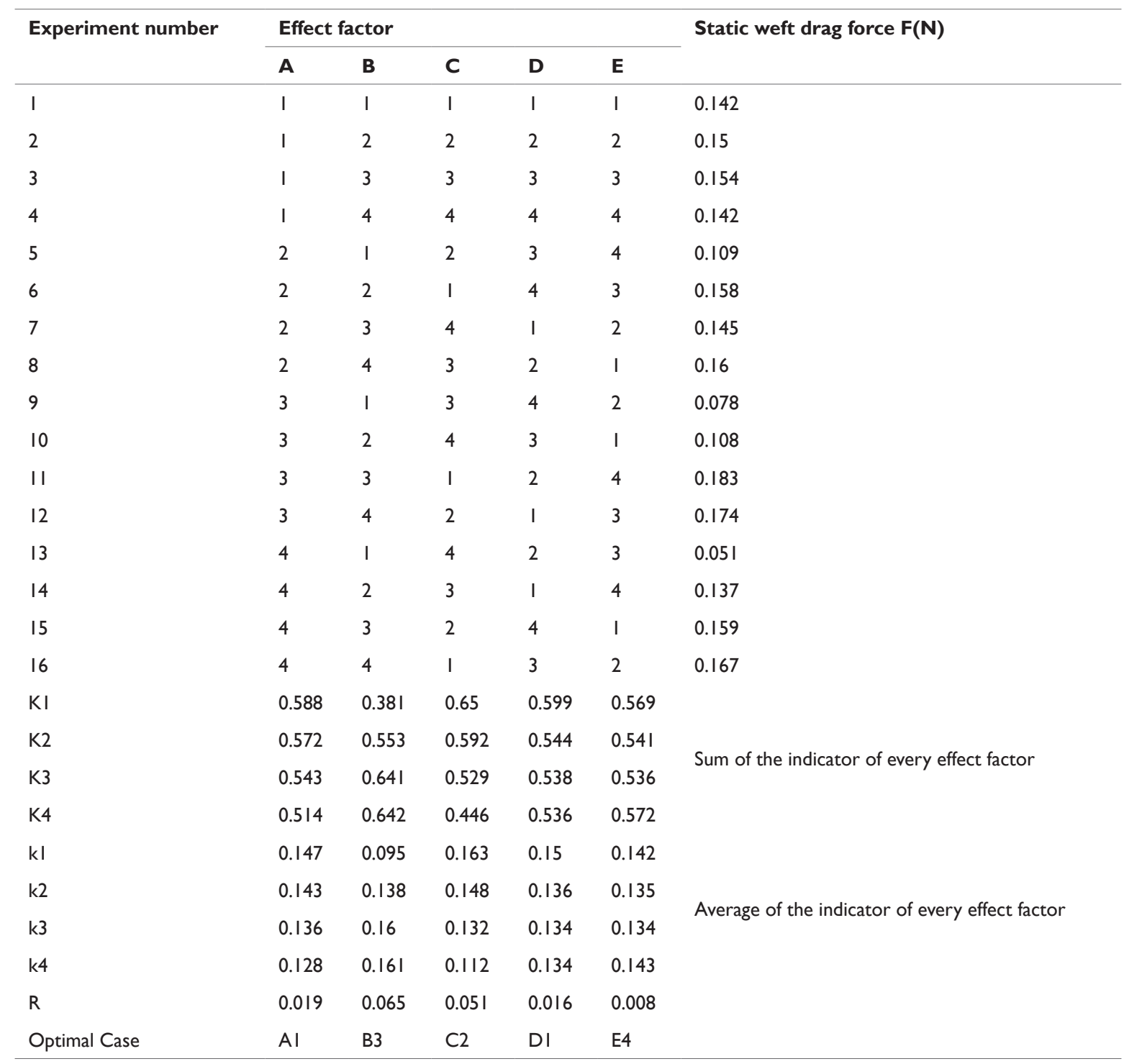

\section{Comparison and conclusion}

Figures 6-8 show the comparison of the air velocity, Mach number and static pressure between the optimal model and the original model, ${ }^{1}$ where the air supply pressure is $0.3 \mathrm{MPa}$. The diameter of acceleration tube, external diameter of needle tip, throat area, and rectifier tank number for the original model are $3 \mathrm{~mm}, 1.9 \mathrm{~mm}, 4.2 \mathrm{~mm}^{2}$, and 8 , respectively, and are $4 \mathrm{~mm}, 2.2 \mathrm{~mm}, 8.75 \mathrm{~mm}^{2}$ and 6 , respectively for the optimal model. Other structural parameters keep constant. From these figures, we can find that the air flow velocity and static pressure have the growing tendency with the increase of acceleration tube diameter and nozzle throat area. As shown in Figure $6 \& 7$, the axial velocity of these two models has little difference in weft guide passage. After being slightly accelerated in cone-shape area, the air velocity remains the same in the straight round pipe and there is not the air leakage phenomenon, which is suitable for weft insertion. As a result of the mixture between the high-pressure flow and atmosphere, the air velocity changed rapidly in weft ejection zone and the backflow zone is produced in two models, where the maximum reaches $0.6 \mathrm{M}$. The length of backflow zone of optimal model is a bit longer than that of the original model, but there is little influence on weft insertion. In acceleration zone, the air velocity of two models is increased gradually, which is accelerated from $273.8 \mathrm{~m} / \mathrm{s}$ of original model to $303.7 \mathrm{~m} / \mathrm{s}$ of optimal model at the nozzle exit. When the air flow is jet into atmosphere, the air velocity is descend rapidly. As the throat area of optimal model is larger than that of original model, the flux is greater than that of the latter and the decrement of air velocity is lower. From above analysis, the air velocity at weft acceleration zone and free jet zone of optimal model is higher than that of the original model, which is benefit for weft insertion.

As shown in Figure 8, the axial static pressure of the two models is stable at an atmosphere in weft guide passage and free jet zone. As a result of the high-speed airflow in nozzle throat, a backflow zone is produced in that area of the two models. The negative pressure of optimal model is lower than that of original model, which is helpful for weft suction from outside. In weft acceleration zone, the air velocity is increased gradually with the decline of static pressure. But the static pressure in acceleration tube of optimal model is higher than that of original model, so that the weft drag force is greater. As 
for cotton yarn, the weft drag force is enlarged from $0.142 \mathrm{~N}$ for the original model to $0.192 \mathrm{~N}$ for the optimized one, and the increasing range is $30 \%$. From above analysis, we can obtain some conclusions on the structure optimization of the main nozzle under the air supply pressure of $0.3 \mathrm{MPa}$ :

i. The axial air velocity and static pressure increases considerably in the assembly of $\mathrm{A}_{1} \mathrm{~B}_{3} \mathrm{C}_{2} \mathrm{D}_{1} \mathrm{E}_{4}$, and the negative pressure of weft ejection zone are lower, which is benefit for the weft insertion.

ii. The weft drag force is greater in the assembly of $\mathrm{A}_{1} \mathrm{~B}_{3} \mathrm{C}_{2} \mathrm{D}_{1} \mathrm{E}_{4}$, which is helpful for the increase of weft velocity.

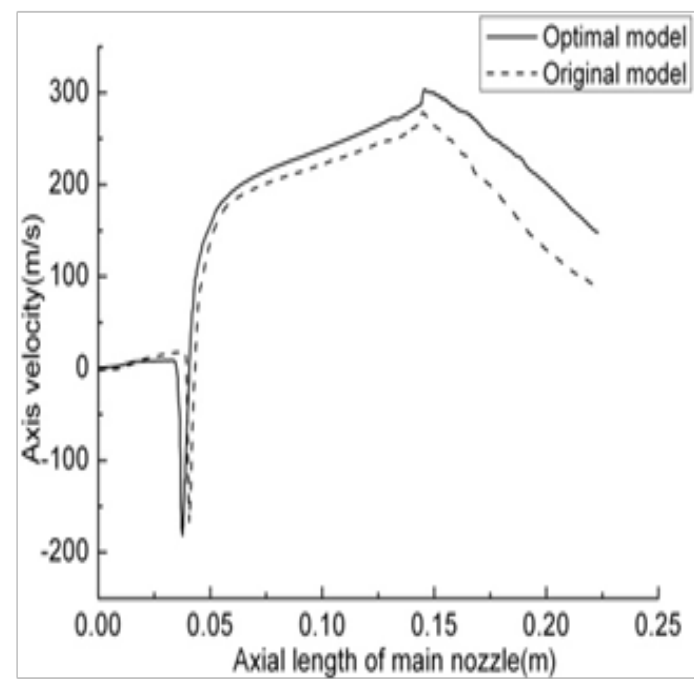

Figure 6 Axial velocity of optimized model and original model.

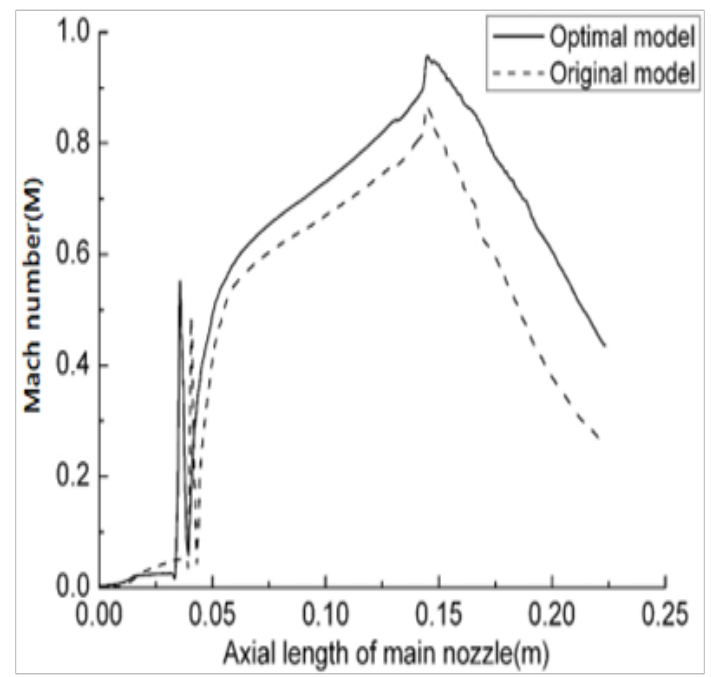

Figure 7 Mach number of optimized model and original model.

Taking the air velocity, static pressure and weft drag force into account, the exit velocity of the main nozzle in the assembly of $\mathrm{A}_{1} \mathrm{~B}_{3} \mathrm{C}_{2} \mathrm{D}_{1} \mathrm{E}_{4}$ has reached high subsonic, the weft drag force is greatly improved and there is no air leakage phenomenon in nozzle entrance. The optimal main nozzle is suitable for weft insertion of high-speed air-jet loom and the analytical method could be used for optimization of other types of main nozzles or different air supply pressure.

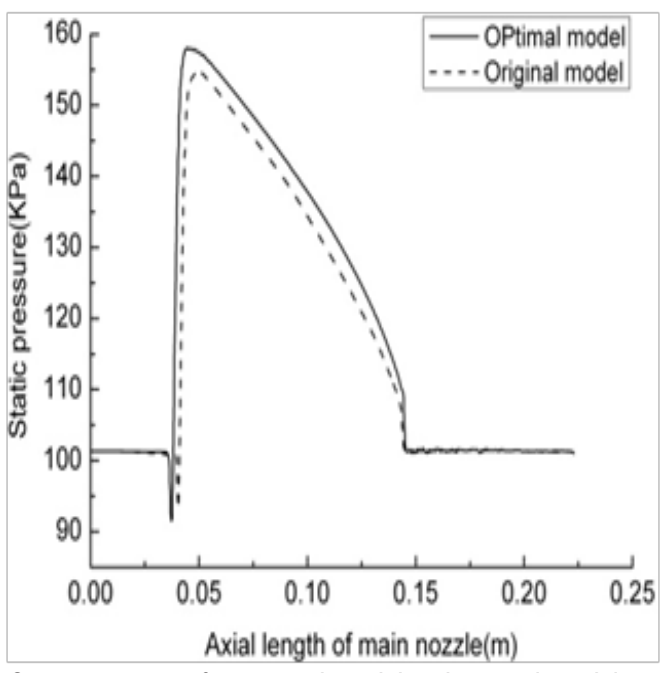

Figure 8 Static pressure of optimized model and original model.

\section{Acknowledgments}

None.

\section{Conflict of interest}

Author declares there is no conflict of interest in publishing the article.

\section{References}

1. Ishida M, Okajima A. Flow Characteristics of the Main Nozzle in an Air-Jet Loom Part I: Measuring Flow in the Main Nozzle. Text Res J. 1994;64(1):10-20.

2. Ishida M, Okajima A. Flow Characteristics of the Main Nozzle in an Air-Jet Loom Part II: Measuring High Speed Jet Flows from the Main Nozzle and Weft Drag Forces. Text Res J. 1994;64(2):88-100.

3. Mohamed MH, Salama M. Mechanics of a Single Nozzle Air-Jet Filling Insertion System Part I: Nozzle Design and Performance. Text Res J. 1986;56(11):683-690.

4. Mohamed MH, Salama M. Mechanics of a Single Nozzle Air-Jet Filling Insertion System Part II: Velocity Distribution and Design of the Air Guide System. Text Res J. 1986;56(12):721-726.

5. Jeong SY, Kim KH, Choi JH, et al. Design of the main nozzle with different acceleration tube and diameter in an air-jet loom. International Journal of Precision Engineering and Manufacturing. 2005;6(1):23-30.

6. Oh TH, Kim SD, Song DJ. A Numerical Analysis of Transonic/Supersonic Flows in the Axisymmetric Main Nozzle of an Air-Jet Loom. Text Res J. 2001;71(9):783-790.

7. Dong-xu Y, Yuan Y, Zhi-hua F. Analysis on the Flow Field of the Main Nozzle in an Air-Jet Loom Based on FLUENT. Journal of Soochow University (Engineering Science Edition, in Chinese). 2007;27(2):14-17.

8. Guo Jie, Feng Zhihua, Zeng Tingwei. 3D analysis on the inner flow field of the main nozzle in air-jet loom based on FLUENT. Journal of Soochow University (Engineering Science Edition, in Chinese). 2009;29(2):38-42.

9. Xiang-Fei L, Zhi-hua F, Zhong-kui S, et al. Calculation and analysis of weft insertion force for air-jet loom's main nozzle based on Fluent. J Text Res (in Chinese). 2011;32(9):125-129. 